\title{
Sustentabilidade: da evolução dos conceitos à implementação como estratégia nas organizações
}

\author{
Lucas Rebello de Oliveira ${ }^{a *}$, Raffaela Martins Medeiros ${ }^{\mathrm{b}}$, \\ Pedro de Bragança Terrac ${ }^{c}$, Osvaldo Luiz Gonçalves Quelhas ${ }^{\mathrm{d}}$ \\ a*lucasrebello.indg@gmail.com, UFF, Brasil \\ braffaelamartins@yahoo.com.br, UFF, Brasil \\ 'pedrodbt@yahoo.com.br, UFF, Brasil \\ ${ }^{\mathrm{d}}$ quelhas@latec.uff.br, UFF, Brasil
}

\section{Resumo}

Este trabalho apresenta uma contextualização acerca da literatura e das diferentes abordagens sobre sustentabilidade nas organizações, relacionando-a com o planejamento estratégico. 0 estudo enquadra-se na Engenharia da Sustentabilidade, uma das áreas do conhecimento definida pela ABEPRO para a Engenharia de Produção. Adaptando os conceitos do Balanced Scorecard (BSC), são propostas diretrizes de gestão, que promovem o alinhamento entre a sustentabilidade e a estratégia, denominada Matriz de Alinhamento Estratégico Sustentável (MAES). Para avaliar a aplicabilidade, foi realizado estudo de caso em uma fabricante de cosméticos. A avaliação da aplicação das diretrizes propostas foi feita a partir da análise das práticas de gestão na organização estudada. Algumas considerações foram feitas acerca dos resultados encontrados, especialmente no que tange ao grau de desenvolvimento ambiental inerente aos processos internos, e são apontadas algumas sugestões de melhoria, no que se refere ao aprimoramento do binômio entre aprendizado e crescimento e o pilar social da sustentabilidade.

Palavras-chave

Gestão estratégica e organizacional. Desenvolvimento sustentável. Planejamento estratégico. Responsabilidade social. Engenharia da sustentabilidade.

\section{Introdução}

Os últimos três séculos foram marcados pelas revoluções industriais e tecnológicas que culminaram com o surgimento de novas técnicas produtivas. Toda essa mudança fez a capacidade de produção aumentar de maneira acelerada. No entanto, tamanha velocidade do crescimento e a consequente necessidade de geração de riquezas acabaram culminando numa série de efeitos colaterais para a sociedade na qual o modelo produtivo se insere, o que levou a questões sobre a impossibilidade de subsistência (MALTHUS, 1998; JEVONS 1865 apud MUELLER, 1998).

Desde então, essa sociedade passou a enfrentar o agravamento de problemas como concentração de riquezas, desigualdade social, desemprego, prejuizos ambientais (CARSON, 1962), novas formas de abordagem em relação ao planeta (BOULDING, 1966), dificuldades nas relações entre as empresas, e destas com a sociedade (FRIEDMAN, 1970; CARROLL, 1979), além de questões relacionadas à própria possibilidade de subsistência. Esses fatores fizeram surgir diversas correntes de pensamentos, estudos e pesquisas, com o objetivo de gerar um modelo que permita aliar estas formas de desenvolvimento com a melhora da interação humana com o meio ambiente e com outros seres humanos.

Todo esse fervor fez com que, em 1968, fosse criado o Clube de Roma, uma organização formada por intelectuais e estudiosos, cujo principal objetivo era discutir assuntos relacionados à política, economia, meio ambiente e desenvolvimento sustentável. Pode-se dizer que seu maior produto foi publicado na reunião de 1972, quando foi apresentado um relatório intitulado "Os Limites do Crescimento". 
Esse estudo, contratado junto ao Massachusetts Institute of Technology (MIT), e liderado por Meadows (1972), se baseava em uma série de modelos matemáticos usados para prever a relação entre o crescimento da população mundial, a industrialização, a produção de alimentos e a diminuição dos recursos naturais. Concluiu-se que, caso as formas de produção continuassem no ritmo apresentado no momento do estudo, os limites de crescimento seriam alcançados em um prazo de 100 anos e, devido a isso, as formas de todos os itens analisados deviam ser "congeladas" de modo que o crescimento fosse contido. Porém, esse estudo foi muito criticado, principalmente por Solow (1974), uma vez que ele pregava a ideia de que era injusto impedir o crescimento dos países pobres, baseado num discurso ecologista, uma vez que esse problema havia sido provocado, principalmente, pelos países ocidentais desenvolvidos.

Em 1973, foi lançado o conceito de Ecodesenvolvimento, pelo francês Maurice Strong, como uma política de desenvolvimento alternativo. Ainda na década de 70, vale destacar as argumentações de UI Haq (1973 apud CAVALCANTI et al., 1994), que defendeu veementemente a separação entre países centrais e países periféricos na elaboração das medidas abordadas no ano anterior sobre o argumento de que os últimos deviam ter garantido seu direito ao desenvolvimento, além de criticar o relatório devido ao fato de os resultados apresentarem muitas variações com a alteração de poucos parâmetros.

A Declaração de Cocoyok, também divulgada em 1973, foi o produto da reunião da Conferência das Nações Unidas sobre Comércio-Desenvolvimento (UNCTAD) e do Programa de Meio Ambiente das Nações Unidas (UNEP), e concluiu que os países industrializados contribuíam para os problemas de subdesenvolvimento devido ao seu alto grau de consumo. O Relatório Dag-Hammarskjöld (1975), estudo elaborado pela UNEP, em conjunto com pesquisadores e políticos de 48 países, veio reforçar a Declaração de Cocoyok, angariando a rejeição dos países desenvolvidos e de pesquisadores mais conservadores (CAVALCANTI et al., 1994).

Diante desse paradigma e das discussões por ele geradas, surgiu em 1987, o termo "Sustentabilidade", sendo apresentado oficialmente na Comissão Mundial sobre Meio Ambiente e Desenvolvimento (CMMAD), da Organização das Nações Unidas (ONU), presidida pela ex-primeira-ministra da Noruega, Gro Harlem Brundtland. Definido como

“[...] a capacidade de satisfazer as necessidades do presente sem comprometer a capacidade das gerações futuras de satisfazerem suas próprias necessidades" (COMISSÃO..., 1988, p. 9).
0 tema foi aceito como prioritário por praticamente todos os países, e isso elevou a importância dessa discussão também no mundo empresarial.

0 conceito do Triple Bottom Line (TBL) ganhou destaque nas discussões devido ao fato de criar um modelo que balizaria as discussões sobre o tema, tornando o assunto mais atrativo para as organizações que ainda não haviam se sensibilizado. Desde então, muitas organizações passaram a comunicar seus desempenhos econômico, ambiental e social e suas inter-relações, baseadas neste conceito (ISENMANN; BEY; WELTER, 2007).

As organizações de grande porte possuem grande interação com o ambiente e as comunidades do entorno da área de operação, demandando, muitas vezes, grandes quantidades de investimento financeiro. Além disso, o crescente número de leis e regulamentações, criadas nos últimos anos, faz com que as questões sustentáveis se tornem praticamente obrigatórias para essas organizações. De acordo com Trevisan et al. (2008, p. 2), a "[...] responsabilidade socioambiental deixou de ser uma opção para as organizações, ela é uma questão de visão, estratégia e, muitas vezes, de sobrevivência”.

No entanto, embora todas elas tenham incluído a busca pela sustentabilidade em suas missões e visões, ainda são raras as empresas reconhecidas como exemplo a ser seguido nesse campo. Isso se deve, principalmente, à falta de um modelo que alie, de forma eficaz, o planejamento estratégico, particularmente o Balanced Scorecard (BSC) (KAPLAN; NORTON, 1996; NORREKLIT, 2000; PRIETO et al., 2006), com os conceitos da sustentabilidade.

0 que se encontra, na prática da gestão empresarial, é uma diversidade de instrumentos de gestão, muitos dos quais de grande qualidade, porém que não demonstram a capacidade de executar tal interação entre a sustentabilidade e a estratégia de negócios na qual a empresa está inserida (BAUMGARTEN, 2002).

Como mencionado acima, o presente estudo tem como objetivo propor diretrizes de gestão, de modo a promover o alinhamento entre a sustentabilidade e a estratégia organizacional. Este modelo denomina-se "Matriz de Alinhamento Estratégico Sustentável (MAES)" e seu estudo se dará em função da apresentação do seu desenvolvimento conceitual e aplicação em uma empresa de grande porte.

A relevância situa-se, dentre outras, na contribuição à elaboração das bases conceituais e metodológicas para a engenharia de produção, no que tange à “engenharia da sustentabilidade”, uma das áreas da engenharia de produção definidas pela Associação Brasileira de Engenharia de Produção (ABEPRO). 


\subsection{Método de pesquisa}

A pesquisa que se desenvolve neste trabalho tem como objeto de estudo sugerir diretrizes de gestão que se propõe a alinhar os princípios da sustentabilidade e a estratégia organizacional. Inicia-se com levantamento bibliográfico sobre os principais conceitos do desenvolvimento sustentável e sua aplicação nas práticas gerenciais das organizações. 0 segundo passo consistiu no estudo das ferramentas de gestão e indicadores mais utilizados: Instituto Ethos, Global Iniciative Report (GRI), Escala Akatu, Índice de Sustentabilidade Empresarial (ISE BOVESPA) e lbase.

Após a apreciação crítica destes modelos, foi feita uma pesquisa de opinião com especialistas, para definir qual dos modelos estudados conseguiria aliar a sustentabilidade, focada principalmente nos três pilares do TBL, aos objetivos, metas e ao plano de ação, oriundos do planejamento estratégico das organizações. Foi constatado, a partir da opinião dos especialistas, que as ferramentas e indicadores de gestão analisados não apresentam abordagem voltada para o alinhamento da estratégia com os princípios da sustentabilidade. Como consequência, o escopo do trabalho definiu-se como uma proposição de ferramenta que permitisse realizar tal interação.

A terceira etapa de elaboração das diretrizes originou-se na mesma pesquisa de opinião de especialistas. Definiu-se a decisão de utilizar o BSC como modelo de alinhamento estratégico, pois tem sido o mais utilizado pelas empresas nos últimos anos. Os autores partiram de premissa de que a utilização de um modelo já difundido no mercado facilitaria a adoção dos conceitos de sustentabilidade na estratégia das organizações. Ainda nesta etapa, as discussões abordaram a forma de interação entre o TBL e o BSC, sem descaracterizar os conceitos de ambos. A solução, para essa questão, foi a proposição de uma matriz, que manteve os pilares consagrados do BSC nas linhas e posicionou os pilares do TBL nas colunas, permitindo uma clara visão do relacionamento dos conceitos descritos a partir de macro-objetivos estratégicos.

A etapa seguinte, a quarta, consistiu na aplicação dessa Matriz através de um estudo de caso. A primeira decisão foi sobre qual empresa seria utilizada como objeto de estudo. Nesse momento, foram avaliadas, qualitativamente, empresas do setor petrolífero, de varejo e de cosméticos, no que tangia à disponibilidade de informações, tamanho da organização, importância no setor e grau de adoção de premissas voltadas para a sustentabilidade em sua estratégia. Após a definição da empresa, foi efetuada a coleta de dados, realizada a partir de informações de domínio público e relatórios de gestão dos anos de 2004, 2005 e 2006, site da empresa, e matérias em jornais e revistas, com o intuito de verificar a validade da sistemática incluída na ferramenta proposta.

A quinta etapa do trabalho foi analisar as informações obtidas e, a partir dos conceitos gerados na MAES, classificar as 65 práticas descritas pela empresa, que foram selecionadas segundo objetivos estratégicos. A última etapa consistiu na avaliação da "sustentabilidade estratégica" por meio de análise crítica. Foi atribuído grau de importância para cada prática e uma nota em função do desempenho, baseados na descrição das atividades vinculadas ao plano de ação estratégico.

Este trabalho parte da premissa de que as empresas que aplicam conceitos de sustentabilidade em suas práticas de gestão buscam aumentar sua eficiência e eficácia operacional e estratégica associadas a tais conceitos. Sendo assim, a pesquisa concentrou-se nos processos de planejamento estratégico e no propósito do alinhamento deste com a sustentabilidade.

\section{Bases do triple bottom line}

0 conceito de sustentabilidade foi oficialmente apresentado na CMMAD (COMISSÃO..., 1988) e, embora o tema tenha obtido aceitação praticamente unânime pelos países que participaram da conferência, existiram diversas críticas. Percebe-se que o objetivo da Comissão Brundtland, ao divulgar este conceito, foi propor uma agenda global, com propósitos de conduzir a humanidade frente aos principais problemas ambientais do planeta e ao progresso, sem comprometer os recursos para as futuras gerações.

Embora tenha sido um grande passo na direção de criar soluções, principalmente para a questão ambiental, a definição foi considerada imprecisa e carregada de utopismo por Drummond (1999). Tal problema foi posteriormente constatado por Rodriguez, Ricart e Sanchez (2002), sob o argumento de que, embora a grande maioria das empresas apresente uma visão de sustentabilidade, esta ainda é voltada, quase que exclusivamente para a questão econômica. Segundo Layrargues (1997), a questão ambiental só ganhou força quando se apresentava como um grave problema no meio produtivo, e só então se iniciou a discussão acerca de "ecoeficiência" e do que seria "politicamente correto".

Mais tarde, na Cúpula da Terra, popularmente conhecida como ECO 92, foi firmado um acordo por quase todos os países do mundo, no qual eles se comprometiam com a estabilização da concentração dos gases responsáveis pelo efeito estufa, porém não foram definidas metas de redução específicas para cada grupo resultante do encontro. Vale ressaltar que 
esse acordo sofre revisões periódicas, sendo, a mais famosa delas, o Protocolo de Quioto apresentado em 1997.

0 conceito do Triple Bottom Line, surgido do estudo realizado por Elkington (1994), no inglês, é conhecido por 3P (People, Planet e Profit); no português, seria PPL (Pessoas, Planeta e Lucro). Analisando-os separadamente, tem-se: Econômico, cujo propósito é a criação de empreendimentos viáveis, atraentes para os investidores; Ambiental, cujo objetivo é analisar a interação de processos com o meio ambiente sem the causar danos permanentes; e Social, que se preocupa com o estabelecimento de ações justas para trabalhadores, parceiros e sociedade.

Juntos, no entanto, estes três pilares se relacionam de tal forma que a interseção entre dois pilares resulta em viável, justo e vivível, e dos três, resultaria no alcance da sustentabilidade, conforme mostrado na Figura 1.

Cabe ressaltar que, recentemente, mais um pilar foi incorporado aos Bottom lines: o pilar cultural. No entanto, este pilar ainda não foi totalmente incorporado pelas organizações como forma de análise para a sustentabilidade. Como o presente estudo tem como objetivo realizar a união de conceitos e modelos com alto grau de aceitação, esse pilar não foi considerado, sendo esta uma melhoria para estudos futuros.

\section{Construção da estratégia a partir do balanced scorecard}

0 conceito da estratégia, que tem origens na Segunda Guerra Mundial, atualmente está difundido no contexto organizacional e demanda um conhecimento da empresa e das influências que esta sofre diante das mudanças políticas, econômicas, culturais e do mercado, impactando diretamente seu poder de concorrência. Toda mudança proporcionada pelo avanço tecnológico e dos meios de produção, além das novas vertentes de discussão sobre o consumo dos recursos naturais e do relacionamento justo das organizações com seus stakeholders, fez com que as organizações passassem de uma ótica de planejamento

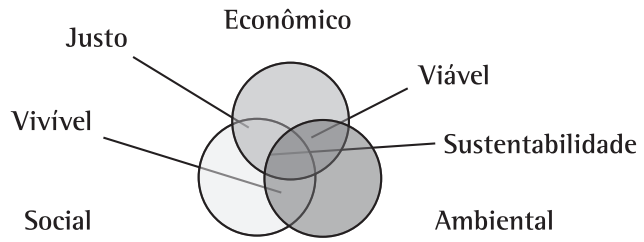

Figura 1. Sustentabilidade e as suas dimensões. Fonte: Adaptado de Alledi Filho et al. (2003, p. 12). financeiro, que, segundo Lobato et al. (2003), não passava de controle financeiro, para uma forma de gestão estratégica, na qual o planejamento e o controle, não somente financeiros, são englobados.

Apesar de inúmeras empresas utilizarem o mecanismo de planejamento estratégico, muitas delas possuem dúvidas quanto ao método de elaboração e seus objetivos específicos. Segundo Ansoff (1990), somente um número reduzido de empresas realiza o verdadeiro planejamento estratégico, que "[...] permite estabelecer a direção a ser seguida pela organização, visando maior grau de interação com o ambiente" (KOTLER, 1975, p. 79).

A direção compreende o âmbito de atuação, macropolíticas, políticas funcionais, filosofia de atuação, macroestratégia, estratégias funcionais, macro-objetivos e objetivos funcionais; enquanto o grau de integração depende do comportamento assumido pela organização com o meio do qual faz parte.

Nesse novo contexto, foi criado o Balanced Scorecard, um instrumento de planejamento e gestão de empresas, desenvolvido há cerca de 10 anos por Robert Kaplan e David Norton, de Harvard, sendo que, atualmente, essa tem sido a metodologia mais difundida nas empresas (PRIETO et al., 2006). Para Hikage, Spinola e Laurindo (2006), o BSC é um sistema de gestão baseado em indicadores de controle interligados logicamente, que permitem a avaliação do desempenho, traduzindo a missão e a estratégia em objetivos e medidas organizados nas perspectivas financeira, dos clientes, dos processos internos, aprendizado e crescimento.

A implantação do BSC se divide entre: a definição clara dos objetivos e estratégias empresariais, além do alinhamento de toda a organização quanto às metas e finalidades; a revisão dos processos existentes e sua avaliação quanto à adequação aos novos propósitos; e, por fim, a criação do mapa estratégico da empresa, que irá mostrar como as relações de causa e efeito se relacionam aos macro-objetivos definidos.

Em suma, o modelo se baseia na mensuração e posterior inter-relação dos seus pilares. Embora os próprios Kaplan e Norton chamem a atenção de que cada empresa defina seus pilares de acordo com sua estratégia e seus interesses; no caso deste estudo, serão utilizados os quatro pilares propostos, para que a estratégia possa ser mais facilmente compreendida. A Figura 2 mostra o modelo de relacionamento entre os pilares do BSC, no qual o planejamento estratégico é baseado no aprendizado e crescimento, que melhoram processos internos e relacionamento com clientes, propiciando ganhos financeiros. 
A perspectiva financeira avalia a lucratividade da estratégia, permitindo a medição e avaliação dos resultados que o negócio proporciona e quais são suas necessidades para crescer e se desenvolver, assim como para satisfazer os seus acionistas. A perspectiva do Cliente identifica os segmentos de mercado visados e as medidas do êxito da empresa nesse segmento. Deve identificar os fatores que são importantes na concepção dos clientes, que é uma das exigências do BSC. E esta preocupação, em geral, situa-se em torno de quatro categorias: tempo, qualidade, desempenho e serviço.

A perspectiva dos processos internos é elaborada após as perspectivas financeira e dos clientes, pois essas fornecem as diretrizes para seus objetivos. Os processos internos são as diversas atividades empreendidas dentro da organização, que possibilitam realizar desde a identificação das necessidades até a satisfação dos clientes. Abrangem os processos de inovação (criação de produtos e serviços), operação (produção e comercialização) e de serviços pós-venda (suporte ao consumidor após as vendas).

A perspectiva do aprendizado e crescimento oferece a base para a obtenção dos objetivos das outras perspectivas, ou seja, é ela que identifica se há infraestrutura necessária para propiciar o crescimento e melhorias a longo prazo, as quais provêm de três fontes principais: pessoas, sistemas e procedimentos organizacionais. Identifica, também, as capacidades de que a empresa deve dispor para conseguir processos internos capazes de criar valor para clientes e acionistas.

Além disso, Prieto et al. (2006) explicita que, para que o modelo tenha êxito, é necessário, além dos fatores anteriormente citados, que a alta direção demonstre claro comprometimento, além da criação de uma estrutura formal que gerencie as atividades de desdobramento das metas e da comunicação dos resultados obtidos.

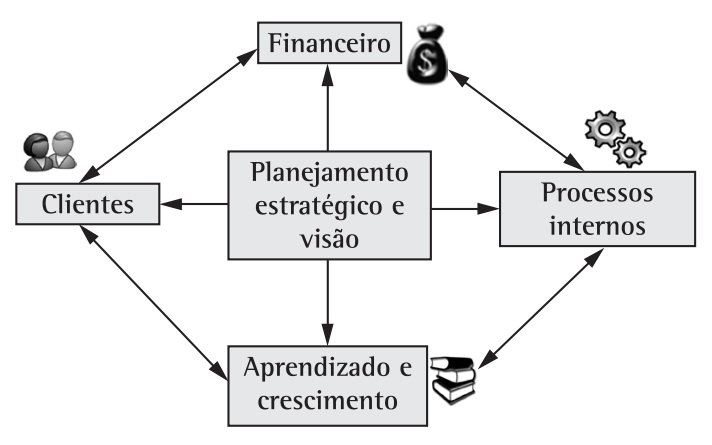

Figura 2. Adaptação do relacionamento entre os pilares do BSC. Fonte: Kaplan e Norton (1997, p. 10).

\section{Diretriz proposta: Matriz de Alinhamento Estratégico Sustentável (MAES)}

Inicialmente, foram analisados os modelos de gestão mais utilizados pelo mercado, de forma a utilizá-los como auxílio na avaliação da sustentabilidade empresarial. Nesta pesquisa, foram avaliados os indicadores do Instituto Ethos (2007), do Global Report Iniciative (GRl, 2007), os indicadores do IBASE (INSTITUTO..., 2007), dentre outros de menor abrangência. Embora todos contribuíssem para a avaliação da sustentabilidade empresarial, não foi percebida uma forma de inserção direta do tema no planejamento estratégico das empresas.

Os indicadores Ethos atuam no binômio socioambiental, sem abordagem financeira específica. A Matriz de Evidência de Sustentabilidade, também do Instituto Ethos, avalia os fatores críticos de sucesso sob o ponto de vista de cada bottom line. 0 GRI deixa em aberto o que cada organização pode definir como social, econômico ou ambiental. 0 IBASE (INSTITUTO..., 2007) prioriza a avaliação social da empresa, ao passo que o Akatu avalia a prática de cada uma, permitindo a comparação, mas sem inserção no processo de alinhamento dos princípios da sustentabilidade com o planejamento estratégico. Deste modo, desenvolveu-se a proposta de diretrizes de gestão que possibilitem tal interação, com o BSC e o TBL, escolhidos como orientadores do alinhamento estratégico. Foi definido que os pilares tradicionais e já consagrados de ambas as ferramentas seriam mantidos. A partir dessa decisão, foi elaborada a arquitetura representada na Figura 3, como estrutura conceitual para relacioná-los. Como consequência do uso da Matriz, deduz-se que investimentos empresariais em recursos humanos e nos demais Stakeholders podem promover melhorias nos processos, no relacionamento com clientes e, consequentemente, obter maior retorno financeiro no que tange à estratégia, ao mesmo tempo que promove progresso na sua relação com o meio ambiente e com as partes interessadas, alcançando, também, sustentabilidade financeira.

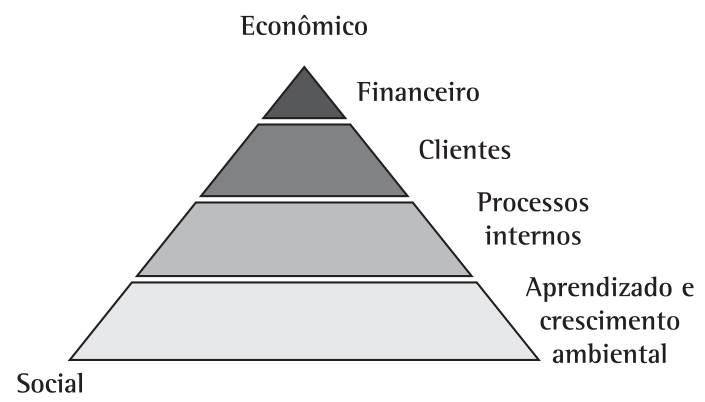

Figura 3 . BSC baseado no Tripple Bottom Line.Fonte: Autores. 
A ferramenta de gestão proposta foi estruturada como uma Matriz de Alinhamento Estratégico Sustentável (MAES), conforme Quadro 1. A Matriz consiste na associação dos macro-objetivos que integram os aspectos estratégicos do BSC às três vertentes da Sustentabilidade.

Esta matriz apresenta objetivos estratégicos genéricos para aliar os pilares da sustentabilidade com os do BSC. No entanto, cada um dos quadrantes tem capacidade de ser subdividido em outros objetivos antes de serem definidos os indicadores estratégicos. Além disso, vale a ressalva de que cada tipo de negócio enfrenta dificuldades próprias, de modo que a matriz pode ser alterada, embora deva estar sempre totalmente preenchida, para que seu propósito de criar ações de planejamento estratégico, em todos os pilares da sustentabilidade, seja alcançado.

Para analisar o grau de aplicabilidade das diretrizes propostas, bem como identificar oportunidades de melhoria, foi efetuado um estudo de caso em empresa de cosméticos, reconhecida pela sua liderança no mercado e pela postura proativa em relação à sustentabilidade. Como mencionado anteriormente, a seleção desta empresa levou em conta a disponibilidade de informações, sua relevância setorial, e as práticas que adota, a fim de que fossem analisados todos os quadrantes da MAES, neste primeiro estudo.

\section{Estudo de caso em uma grande empresa brasileira}

\subsection{Contextualização}

A empresa em questão é líder no mercado nacional de cosméticos, fragrâncias e higiene pessoal, e sua marca está entre as mais valorizadas do País. Conta com cerca de 900 produtos em seu portfólio, nas categorias maquiagem, perfumaria, proteção solar, cuidados com rosto, corpo, cabelos, entre outros. Possui atividades em diversos países e, ainda assim, mantém-se firme em relação à ideia de que a empresa é um organismo vivo, um dinâmico conjunto de relações. Seu comprometimento crescente com práticas responsáveis de gestão dos negócios, nas últimas décadas, fez com que esse tema adquirisse nova dimensão.

Segundo a política da qualidade da empresa, o objetivo é consolidar-se como referência na qualidade de processos e produtos na indústria cosmética e alcançar "classe mundial" na qualidade dos serviços e relacionamentos, de modo a construir uma marca de excelência reconhecida por todos os seus públicos. Nesse sentido, a sua Política de Qualidade define diretrizes para monitorar e promover a melhoria contínua necessária ao desenvolvimento dos negócios. Com a sua aplicação, a empresa busca superar positivamente as expectativas dos seus clientes, sendo estes compostos por: consumidores, consultores, fornecedores, acionistas, colaboradores, comunidades, governos e sociedade.

A partir de pesquisa em materiais de conhecimento público, como os relatórios de gestão de 2004 a 2006, site, e uma pesquisa de campo, foram coletadas e analisadas, qualitativamente, diversas práticas de gestão adotadas pela empresa e destas, selecionadas 65 , que, posteriormente, foram agrupadas segundo os quadrantes da MAES. A descrição das práticas, o objetivo estratégico no qual elas foram inseridas, sua importância para a sustentabilidade e a nota atribuída pelos autores para avaliá-las podem ser vistos nas tabelas contidas no Anexo 1.

Quadro 1. Matriz para Alinhamento da Estratégia Sustentável (MAES).

\begin{tabular}{|c|c|c|c|}
\hline Pilares & Social & Econômico & Ambiental \\
\hline Financeiro & $\begin{array}{l}\text { Distribuição de ganhos às partes } \\
\text { interessadas (fornecedores, } \\
\text { distribuidores, comunidades, e demais } \\
\text { interessados) } \\
\text { Criação de estrutura que sustente outras } \\
\text { atividades na região }\end{array}$ & $\begin{array}{l}\text { Maximização dos lucros } \\
\text { Maximização das receitas }\end{array}$ & $\begin{array}{l}\text { Investimentos em tecnologias alinhadas } \\
\text { aos conceitos de P+L e de inovação } \\
\text { Participação em índices de } \\
\text { sustentabilidade } \\
\text { Participação no programa de créditos } \\
\text { de carbono }\end{array}$ \\
\hline Clientes & $\begin{array}{l}\text { Aumento da percepção externa quanto } \\
\text { ao seu comprometimento social através } \\
\text { do desenvolvimento de programas } \\
\text { sociais junto aos órgãos públicos ou } \\
\text { privados }\end{array}$ & $\begin{array}{l}\text { Aumento da participação no mercado } \\
\text { Retenção de clientes } \\
\text { ldentificação de novos mercados }\end{array}$ & $\begin{array}{l}\text { Aumento da percepção externa quanto } \\
\text { ao seu comprometimento ambiental } \\
\text { com o desenvolvimento de programas } \\
\text { ambientais }\end{array}$ \\
\hline $\begin{array}{l}\text { Processos } \\
\text { Internos }\end{array}$ & $\begin{array}{l}\text { Transparência, ética e tratamento } \\
\text { justo nos relacionamentos } \\
\text { intraorganizacionais (seleção, avaliação } \\
\text { e contato com todos os stakeholders) }\end{array}$ & $\begin{array}{l}\text { Otimização de processos produtivos } \\
\text { internos e externos } \\
\text { Estabelecimento de padronização, } \\
\text { reduzindo erros e desperdicios }\end{array}$ & $\begin{array}{l}\text { Exigência de práticas ambientalmente } \\
\text { corretas nos processos } \\
\text { intraorganizacionais } \\
\text { Implantação de normas ambientais }\end{array}$ \\
\hline $\begin{array}{l}\text { Aprendizado e } \\
\text { Crescimento }\end{array}$ & $\begin{array}{l}\text { Desenvolvimento cultural e educacional } \\
\text { dos stakeholders do processo }\end{array}$ & $\begin{array}{l}\text { Investimento no desenvolvimento de } \\
\text { competências necessárias e aderentes } \\
\text { aos resultados da organização }\end{array}$ & $\begin{array}{l}\text { Conscientização, desenvolvimento e } \\
\text { multiplicação de cultura ambientalmente } \\
\text { responsável }\end{array}$ \\
\hline
\end{tabular}

Fonte: Oliveira, Terra e Medeiros (2007, p. 42). 


\subsection{Aplicação do modelo}

Para efetuar o agrupamento das práticas em objetivos, foram necessários dois passos: o primeiro era definir em qual bottom line a prática seria enquadrada; e o segundo, com qual pilar do BSC ela apresentaria maior afinidade de conceitos. Algumas práticas poderiam ser posicionadas em mais de um quadrante; todavia, para simplificar a avaliação, foi considerado apenas o quadrante principal, no qual cada uma foi classificada a partir da interpretação dos autores.
0 resultado da análise das práticas organizacionais selecionadas, agrupadas à luz dos conceitos do modelo proposto, teve como produto a definição dos objetivos estratégicos da organização, descritos no Quadro 2, e a proposição dos relacionamentos desses objetivos, que podem ser observados através do esquema apresentado na Figura 4.

Uma vez concluída a proposição do "Mapa Estratégico Sustentável” da empresa, foi identificada a necessidade de algum tipo de avaliação sobre qual

Quadro 2. Descrição dos objetivos estratégicos da empresa.

\begin{tabular}{|c|c|c|c|}
\hline & (S) - Social & (E) - Econômico & (A) - Ambiental \\
\hline $\begin{array}{l}(\mathrm{F})- \\
\text { Financeiro }\end{array}$ & $\begin{array}{l}\text { SF1 - Propiciar geração de renda na } \\
\text { comunidade do entorno } \\
\text { SF2 - Propiciar geração de renda para } \\
\text { colaboradores, fornecedores e parceiros }\end{array}$ & $\begin{array}{l}\text { EF1 - Gerar valor à marca } \\
\text { EF2 - Aumentar EBITDA }\end{array}$ & $\begin{array}{l}\text { AF1 - Investir em tecnologias } \\
\text { ambientalmente corretas } \\
\text { AF2 - Estabelecer e buscar o alcance de } \\
\text { metas econômicas compativeis com o } \\
\text { desenvolvimento sustentável }\end{array}$ \\
\hline $\begin{array}{c}\text { (C) - } \\
\text { Clientes }\end{array}$ & $\begin{array}{l}\text { SC1 - Publicar dados e relatórios } \\
\text { baseados em indicadores sociais } \\
\text { SC2 - Promover os projetos sociais } \\
\text { desenvolvidos }\end{array}$ & $\begin{array}{l}\text { EC1 - Estabelecer canais de } \\
\text { comunicação } \\
\text { EC2 - Aumentar o valor agregado dos } \\
\text { produtos ou serviços }\end{array}$ & $\begin{array}{l}\text { AC1 - Buscar satisfação de clientes } \\
\text { preocupados com meio ambiente e } \\
\text { qualidade de vida } \\
\text { AC2 - Difundir práticas ambientais }\end{array}$ \\
\hline $\begin{array}{l}(\mathrm{P})- \\
\text { Processos } \\
\text { internos }\end{array}$ & $\begin{array}{l}\text { SP1 - Buscar relação "ganha - ganha” } \\
\text { com fornecedores } \\
\text { SP2 - Estabelecer políticas de benefícios, } \\
\text { salários e condições dignos } \\
\text { SP3 - Promover satisfação dos } \\
\text { stakeholders }\end{array}$ & $\begin{array}{l}\text { EP1 - Buscar indicadores com alto nível } \\
\text { de exigência } \\
\text { EP2 - Automação da produção } \\
\text { EP3 - Investimento em P\&D }\end{array}$ & $\begin{array}{l}\text { AP1- Reverter processos nocivos ao meio } \\
\text { ambiente } \\
\text { AP2 - Minimizar processos nocivos ao meio } \\
\text { ambiente } \\
\text { AP3 - Adequar-se às normas e legislações } \\
\text { ambientais }\end{array}$ \\
\hline $\begin{array}{l}(\mathrm{A})- \\
\text { Aprendizado } \\
\mathrm{e} \\
\text { crescimento }\end{array}$ & $\begin{array}{l}\text { SA1 - Capacitar e desenvolver pessoas } \\
\text { nos centros de produção e consumo } \\
\text { SA2 - Construir parcerias com } \\
\text { universidades, Centros Tecnológicos e } \\
\text { órgãos governamentais }\end{array}$ & $\begin{array}{l}\text { EA1 - Prover treinamento técnico e } \\
\text { capacitação aos colaboradores. } \\
\text { EA2 - Promover o desenvolvimento de } \\
\text { fornecedores e parceiros. }\end{array}$ & $\begin{array}{l}\text { AA1 - Internalização dos conceitos de } \\
\text { responsabilidade ambiental. } \\
\text { AA2 - Buscar novas técnicas de consumo } \\
\text { sustentável }\end{array}$ \\
\hline
\end{tabular}

Fonte: Adaptado de Oliveira, Terra e Medeiros (2007, p. 54).

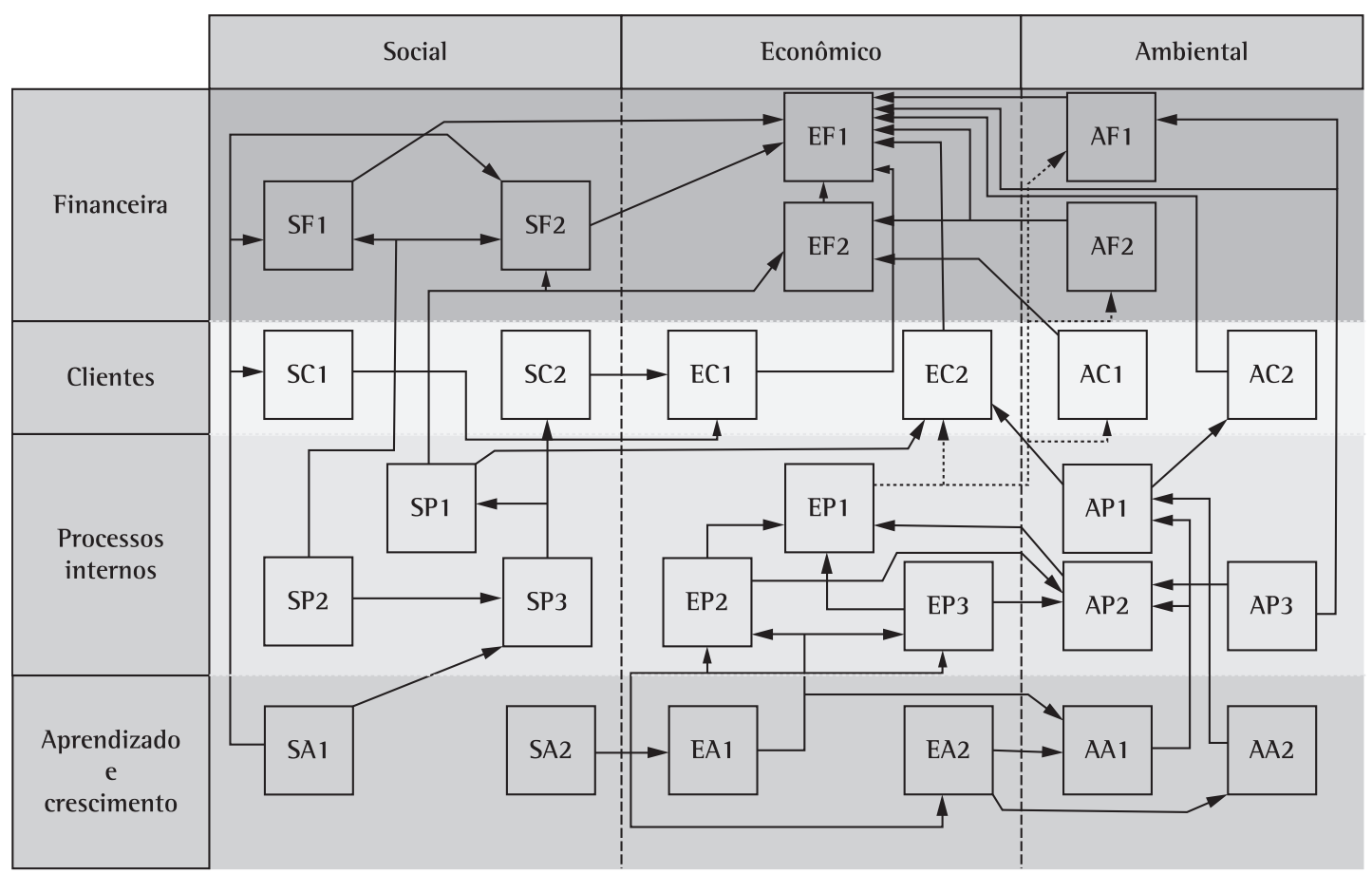

Figura 4. Mapa estratégico sustentável. Fonte: Adaptado de Oliveira, Terra e Medeiros (2007, p. 54). 
quadrante estaria mais desenvolvido e quais seriam as maiores oportunidades de melhoria da empresa. Para isso, foi elaborada avaliação, na qual foram atribuídas notas que variavam de 1 a 5 . Isto para avaliar a relevância e o desempenho da prática diante da estratégia de sustentabilidade. A pontuação obedeceu à seguinte classificação: 1) Relevância muito baixa; 2) Relevância fraca; 3) Relevância média; 4) Relevância considerável; 5) Relevância alta. Ao final, foi possível avaliar o grau de alocação da empresa, segundo os princípios da sustentabilidade e os pilares do BSC.

Após o processo de avaliação, o qual buscou quantificar as práticas, foi elaborada a Figura 5, no qual é possível avaliar os resultados de cada um dos pilares do BSC dentro dos bottom lines. Nessa fase, os objetivos estratégicos propostos poderiam ter sido também avaliados individualmente; no entanto, como o objetivo do estudo de caso era avaliar a inserção da sustentabilidade no planejamento estratégico, as análises foram feitas de forma abrangente, ou seja, levando em conta apenas o desempenho dos quadrantes. Para facilitar a análise, foi elaborado um resumo das notas, apresentado no Quadro 3.

\subsection{Análise dos resultados}

A partir dos resultados gerados na etapa anterior, foi percebido que o pilar ambiental demonstra sua força tanto pela quantidade de práticas descritas, quanto pelo aparente grau de maturidade delas. 0 quadrante

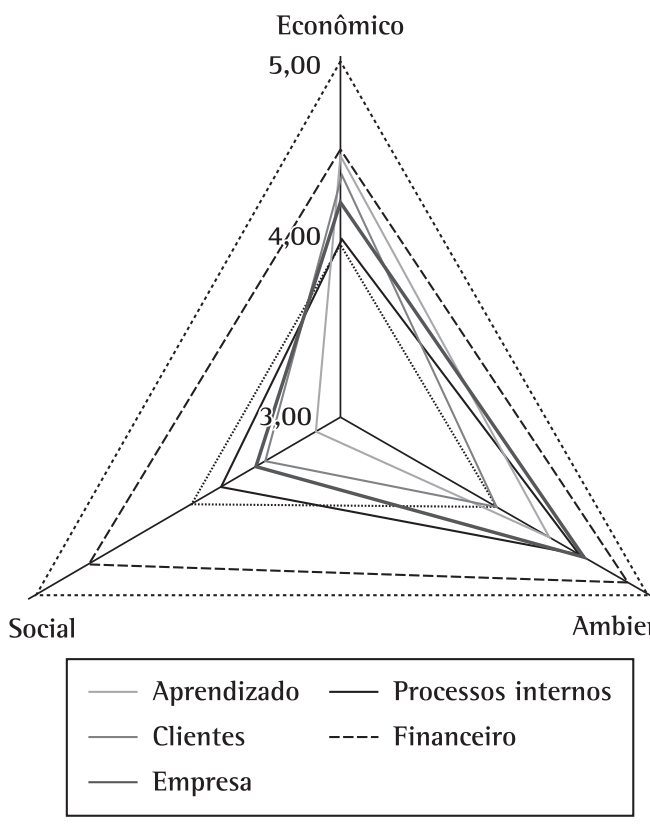

Figura 5. O BSC na sustentabilidade. Fonte: Adaptado de Oliveira, Terra e Medeiros (2007, p. 56). financeiro, de maior desenvolvimento neste pilar, tem como base as atividades com uso extremamente racional dos recursos naturais, de forma a tornar a operação rentável. Este fato também é reforçado pelo relacionamento com o segundo e terceiro quadrantes mais desenvolvidos, o de processos internos e de aprendizado, os quais apresentam uma série de práticas orientadas à mudança de processos, segundo práticas de produção mais limpa. 0 quadrante de clientes obteve resultado inferior apesar da participação da empresa em importantes órgãos de discussão. Nesse campo, observou-se uma defasagem no que tange à divulgação das ações ambientais. Apesar da existência de práticas, a empresa não demonstrou ter investido nesse quadrante na época da pesquisa. A razão pode ser atribuída ao fato de a empresa ter uma imagem de relacionamento com o meio ambiente já consolidada no mercado.

0 pilar econômico apresentou bons resultados nos quesitos financeiros e de aprendizado; entretanto, este efeito se deve à pouca quantidade de práticas existentes nestes quadrantes, que, por terem tido boa avaliação, elevaram a média, ainda que necessitem ganhar mais maturidade. Um exemplo disso é o fato de a única prática classificada como econômico-financeira ser a execução de hedges, para se proteger de eventuais variações cambiais, o que parece pouco para uma empresa de grande porte, que é líder no segmento. A definição de dois objetivos estratégicos, nesse quadrante, se deu ao fato de que as organizações buscam sempre valorizar sua marca, independentemente de ter ações específicas voltadas para este fim. Ainda neste bottom line, o pilar de processos internos, apesar de ter tido pontuação inferior, se mostra relativamente desenvolvido e em concordância com a MAES, uma vez que existem diversas práticas de otimização de processos e de estabelecimento de padrões de produção mais elevados.

Por sua vez, o pilar social apresentou a maior quantidade de práticas descritas, porém mostrou-se mais afastado do resultado global. Isso se deve, principalmente, ao fato de a empresa apresentar grau de maturidade bastante restrito ao quadrante financeiro, apoiando projetos incorporados à operação de outras empresas e permitindo aumentar

Quadro 3 . Resultado Ponderado da avaliação das práticas sustentáveis. Fonte: Autores.

\begin{tabular}{|c|c|c|c|}
\hline BSC & Social & Econômico & Ambiental \\
\hline Financeiros & 네 4,67 & 넨 4,50 & 4,86 \\
\hline Clientes & all 3,50 & Alll 4,33 & 네 4,00 \\
\hline Processos internos & IIII 3,80 & 4اله 4,00 & ill 4,56 \\
\hline Aprendizado e crescimento & alll 3,15 & 4lll 4,50 & 세 4,50 \\
\hline
\end{tabular}


as finanças tanto dos seus parceiros quanto dos seus distribuidores. Ao passo que, no quadrante de aprendizado e crescimento e de processos internos, existem muitas ações que não se encontram alinhadas aos conceitos da MAES: no que diz respeito ao pilar de aprendizado, as ações são importantes apenas num contexto de manutenção das atividades da empresa no local, ou seja, a comunidade do entorno não teria condições de manter seu padrão de vida atual sem a organização. Outro ponto percebido foi a falta de informações sobre critérios de avaliação e seleção de fornecedores e parceiros, o que impossibilitou uma melhor avaliação deste pilar no âmbito dos processos internos.

Dentre as melhorias a serem efetuadas no processo de avaliação, destacam-se a definição e um número mínimo de práticas ou indicadores, que permitam efetuar uma análise mais efetiva do grau de sustentabilidade das práticas organizacionais, utilizar alguma metodologia com base matemática, tanto para distribuir pesos entre os quadrantes da MAES, quanto para ponderar a importância dos objetivos estratégicos dentro destes. Com o intuito de ampliar o nível de conhecimento da organização sobre gestão sustentável, podem ser criados indicadores para cada grupo, estudar como estes indicadores podem afetar não só o seu objetivo como os demais, se positiva, ou negativamente, em função do seu desempenho.

Apesar destas oportunidades de melhoria, uma vez concluído o estudo de caso, pode-se constatar que as diretrizes de análise propostas demonstraram sua aplicabilidade. No entanto, a falta de acesso a todos os indicadores e dados existentes, fato este justificado por uma norma da organização de ceder informações sigilosas exclusivamente para trabalhos de pós-graduação, fez com que a análise fosse pautada apenas nas práticas descritas em relatórios de gestão, e, eventualmente, descritas durante a visita técnica. Contudo, apesar deste empecilho, foi possivel esboçar um mapa estratégico que alinhasse as questões sustentáveis ao BSC.

\section{Conclusões e sugestões de futuras pesquisas}

Dentre as áreas da engenharia de produção, incluídas nas definições da Associação Brasileira de Engenharia de Produção ABEPRO, a Engenharia da Sustentabilidade aborda o tema constante neste artigo. Desenvolver ferramentas de gestão e modelos analíticos de inserção das questões ambientais, sociais e econômicas nas decisões de desenvolvimento de produtos, processos, gerência da produção e na logística constitui demanda contemporânea para pesquisadores e gestores. Nesse contexto, este estudo situa-se como contribuição a esta área do conhecimento da engenharia de produção.

A pesquisa apoiou-se em estratégia prescritiva para propor a ferramenta. lsto oferece, de imediato, a perspectiva de implementação para teste e identificação de oportunidades de melhoria. Uma das barreiras ao uso dessa ferramenta é a ausência de conhecimento organizacional sobre as necessidades ambientais e sociais inerentes aos seus stakeholders. Torna-se pré-requisito, portanto, assumir a relevância de conhecer os stakeholders, identificar suas necessidades, hierarquizá-las e priorizar, segundo disponibilidade de tempo e recursos financeiros. Um dos objetivos deste trabalho, além do levantamento das práticas empresariais associadas aos conceitos da responsabilidade social e de adaptar o conceito do Balanced Scorecard para "medir" a sintonia entre as estratégias empresariais e os princípios da sustentabilidade, consiste em identificar caminhos para difundir o uso de modelos analíticos e conferir racionalidade à adoção de encargos de investimento por parte das organizações brasileiras em termos de responsabilidade socioambiental, constituindo-se em escopo da Engenharia de Produção.

Considera-se fundamental, a fim de estruturar melhor o uso da ferramenta proposta, a existência de um conjunto de iniciativas possíveis para se alcançar esse fim. Deve-se considerar, também, a introdução de modelos analíticos de apoio e suporte à decisão nas empresas para investir em ações orientadas para a sustentabilidade. 0 que resulta em princípios não excludentes:

i) incentivar iniciativa voluntária dos profissionais da organização;

ii) inclusão de profissionais motivados para a sustentabilidade e sua participação no planejamento estratégico;

iii) desenvolvimento e implantação de indicadores estratégicos, táticos e operacionais (nos âmbitos social, econômico e ambiental);

iv) estabelecer processo interno de participação dos diversos níveis hierárquicos na formulação dos objetivos e metas estratégicos vinculados à sustentabilidade organizacional;

v) estabelecer vínculo entre o plano de desenvolvimento de carreira ao engajamento dos profissionais à sustentabilidade organizacional.

Por fim, a atividade de consultoria, desempenhada por profissionais ligados às empresas privadas ou mesmo ao meio acadêmico, constitui um importante canal para difusão de modelos de gestão organizacional apoiados no tripé social, ambiental e econômico. 
Embora a pesquisa tenha sido realizada em apenas uma empresa, dada sua representatividade e a relevância dos resultados, pode-se inferir que a utilização do modelo proposto auxilia auferir se as organizações estão efetivamente vinculando ações, projetos e programas à "sustentabilidade organizacional ou empresarial". A despeito dos grandes investimentos em projetos socioambientais, pouco se identifica, nas práticas empresariais brasileiras, a sintonia entre os objetivos e metas estratégicas e tais projetos. Sendo assim, um dos possíveis indicadores de medição dos objetivos estratégicos propostos na MAES poderia derivar da evolução do projeto, caso este estivesse em fase de implantação, ou dos resultados por ele gerados.

A aproximação entre os centros de pesquisa e as organizações tem-se mostrado um caminho para o desenvolvimento de pesquisas e a consequente geração de novos conhecimentos em gestão organizacional sustentável. Na área de Engenharia de Produção e, em particular, da Gestão da Produção, acredita-se que seja importante dar relevância à pesquisa com estudo de caso de desenvolvimento e implantação de modelos vinculados à sustentabilidade nas organizações.

Devido a isso, o presente estudo preenche lacuna existente com relação a uma ferramenta de alinhamento entre a sustentabilidade e o planejamento estratégico. Como contribuição para o desenvolvimento sustentável, sublinha-se o esforço tanto acadêmico quanto empresarial, para que o tema deixe de ser utopia e passe a ser realidade nas ações efetivas nas organizações brasileiras.

\section{Referências}

ALlEDI FILHO, C.; QUELHAS, 0. L. G.; SILVA, E. N. C.; RODRIGUEZ, M. Melhoria Contínua baseada na capacidade de aprendizado da indústria de petróleo: guia visual para implementação do ambiente do conhecimento. Revista Inteligência Empresarial, COPPE/UFRJ, n. 13, 2003.

ANSOFF, H. l. General management in turbulent environments. Practising Manager, v. 11, n. 1, p. 6-27, 1990.

BAUMGARTEN, M. Conhecimento, planificação e sustentabilidade. São Paulo em Perspectiva, v. 16, n. 3, p. 31-41, 2002.

BOUDING, K. E. The economics of the coming spaceship earth. In: JARRETT (Ed.) Environmental quality in a growing economy. Baltimore: Johns Hopkins Press, 1966.

CARROLL, A. B. A three-dimensional conceptual model of corporate performance. Academy of Management Review, v. 4, p. 497-505, 1979.

CARSON, R. Silent spring. 1962. Disponivel em: <http:// ambientaressaealutablogspot.com/ 2008/07/primaverasilenciosa.html>. Acesso em: 22 mar. 2009.

CAVALCANTI, C. et al. (Org.). Desenvolvimento e natureza: estudos para uma sociedade sustentável. Recife, Brasil: Instituto de Pesquisas Sociais - INPSO; Fundação Joaquim Nabuco FUNDAJ; Ministério de Educacão, 1994. 262 p. Disponível em: <http://168.96.200.17/ar/libros/brasil/pesqui/cavalcanti. rtf>. Acesso em: 20 fev. 2007.
COMISSÃO MUNDIAL SOBRE MEIO AMBIENTE E DESENVOLVIMENTO - CMMAD. Nosso futuro comum. Rio de Janeiro: Fundação Getúlio Vargas, 1988.

DRUMMOND, J. A. Desenvolvimento sustentável: debates em torno de um conceito problemático. História, Ciências, Saúde, v. 5, n. 3, p. 755-761, 1999.

ELKINGTON, J. Triple bottom line revolution: reporting for the third millennium. Australian CPA, v. 69, p. 75, 1994.

FRIEDMAN, R. E. The Social responsability of business is to increase its profits. New York Times Magazine, 13 set. 1970.

HIKAGE, O. K.; SPINOLA, M. M.; LAURINDO, F. J. B. Software de balanced scorecard: proposta de um roteiro de implantação. Revista Produção, v. 16, n. 1, p. 140-160, 2006.

INSTITUTO Brasileiro de Análises Sociais e Econômicas - IBASE. Disponível em: <http://www.ibase.br/userimages/balanco_ social_2006.pdf>. Acesso em: 27 jan. 2007.

INSTITUTO ETHOS de Empresas e Responsabilidade Social ETHOS. Disponivel em: <http://www.ethos.org.br/docs/ conceitos_praticas/indicadores/download/indicadores_2006. pdf>. Acesso em: 04 fev. 2007.

ISENMANN, R.; BEY, C.; WELTER, M. Online reporting for sustainability issues. Business Strategy and the Environment, v. 16, p. 487-501, 2007. http://dx.doi.org/10.1002/bse.597

KAPLAN, D.; NORTON, R. A estratégia em ação. Rio de Janeiro: Campus, 1997.

KAPLAN, R. S.; NORTON, D. P. Using the balanced scorecard as a strategic management system. Harvard Business Review, 1996.

KOTLER, P. Administração de marketing. São Paulo: Atlas, 1975.

LAYRARGUES, P. P. Do ecodesenvolvimento ao desenvolvimento sustentável: evolução de um conceito, 1997.

LOBATO D. M. et al. Estratégia de empresas. Rio de Janeiro: FGV, 2003.

MALTHUS, T. R. An essay on the principle of population. Reprint. Amherst, NY: Prometheus Books, 1998.

MEADOWS, D. H. et al. The limits to growth. 1972.

MUELLER, C. C. Avaliação de duas correntes da economia ambiental: a escola neoclássica e a economia da sobrevivência. Revista de Economia Política, v.18, n. 2, 1998.

NORREKLIT, $\mathrm{H}$. The balance on the balanced scorecard a critical analysis of some of its assumptions. Management Accounting Research, v. 11, p. 65-88, 2000. http://dx.doi. org/10.1006/mare.1999.0121

OLIVEIRA, L. R.; TERRA, P. B.; MEDEIROS, R. M. Projeto final de graduação: gestão da sustentabilidade nas organizações brasileiras. 2007

PRIETO, V. C. et al. Fatores críticos na implementação do Balanced Scorecard. Gestão \& Produção, v. 13, n. 1, p. 81-92, 2006. http://dx.doi.org/10.1590/S0104-530X2006000100008

RODRIGUEZ, M. A.; RICART, J. E.; SANCHEZ, P. Sustainable development and sustainability of competitive advantage: a dynamic sustainable view of the firm. 2002.

SOLOW, R. M. The economics of recources or the the resources of economics. American Economic Review, v. 19, n. 2, p. 1-14, 1974.

THE GLOBAL Reporting Initiative - GRI. Disponível em: <http:// www.globalreporting.org/NR/rdonlyres/4855C490-A8724934-9E0B-8C2502622576/2612/AL_G3_Portuguese BR.pdf>. Acesso em: 27 jan. 2007.

TREVISAN, M. et al. Uma ação de responsabilidade socioambiental no rodeio internacional. In: ENCONTRO NACIONAL DE ENGENHARIA DE PRODUÇÃO - ENEGEP, 28., 2008, Rio de Janeiro. Anais.. 


\section{Sustainability: the evolution of concepts to implementation as strategy in organizations}

\section{Abstract}

This paper presents a background on the literature and different approaches to sustainability in organizations, linking it to strategic planning. The study was based on Engineering of Sustainability, one of the knowledge areas defined by ABEPRO for Production Engineering. Adapting the concepts of Balanced Scorecard (BSC), there were proposed management guidelines, which promoted the alignment between sustainability and strategy - called Matrix of Sustainable Strategic Alignment (MSSA). In order to evaluate its applicability, a case study was conducted in a cosmetics manufacturer. The assessment of the proposed guidelines implementation was made from the analysis of management practices in the studied organization. Some considerations were made about the results, especially regarding the degree of environmental development inherent to the internal processes. This study pointed out some suggestions for improvement regarding the binomial: learning \& growth and the social pillar of sustainability.

\section{Keywords}

Strategical and organizational management. Sustainable development. Strategic planning. Social responsibility. Engineering of sustainability.

Anexo 1. A seguir serão apresentadas práticas organizacionais utilizadas para a proposição dos objetivos estratégicos, bem como sua pontuação com relação à relevância da sustentabilidade, a nota atribuída pelos autores para a maturidade da prática e o objetivo estratégico no qual cada uma foi enquadrada.

Tabela 1. Evidências de práticas empresariais sociais, perspectiva: aprendizado e crescimento.

\begin{tabular}{|c|c|c|c|c|}
\hline Práticas sociais com breve descrição & 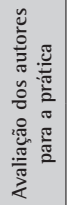 & 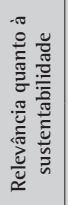 & 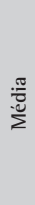 & 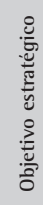 \\
\hline \multicolumn{5}{|l|}{ Aprendizado e cresimento } \\
\hline $\begin{array}{l}\text { Convite para vendedoras e vendedores livres para participar de projetos de impactos sociais e ambientais como agentes mobilizadores para } \\
\text { seus consumidores e suas comunidades. }\end{array}$ & 4 & 1 & 4 & SA 1 \\
\hline Promoção de matrículas e rematrículas no programa Educação de Jovens e Adultos, encaminhados por vendedores livres. & 3 & 1 & 3 & SA1 \\
\hline Desenvolvimento do Programa Competências Básicas Profissionais para portadores de deficiência em parceria com o Senai. & 5 & 1 & 5 & $\mathrm{SA} 2$ \\
\hline Desenvolver vendedoras e vendedores livres para desempenhar papel de agentes de transformação social, econômica e ambiental. & 3 & 1 & 3 & SA 1 \\
\hline $\begin{array}{l}\text { Desenvolvimento do Projeto de Incentivo à Leitura em parceria com as ONGs Ação Educativa, Alfabetização Solidária e Centro de Estudos } \\
\text { e Pesquisas em Educação, Cultura e Ação Comunitária. }\end{array}$ & 3 & 1 & 3 & SA 1 \\
\hline $\begin{array}{l}\text { Na área cultural,a empresa apoia iniciativas que dão visibilidade ao patrimônio musical brasileiro. Desenvolve um programa de patrocínio } \\
\text { cultural que identifica,apoia e destaca ações que representem a qualidade e a diversidade da música brasileira. }\end{array}$ & 2 & 1 & 2 & SA 1 \\
\hline $\begin{array}{l}\text { Mobilização das vendedoras e vendedores livres para que levassem,além dos produtos e conceitos da organização, seus valores no âmbito } \\
\text { social e no ambiental. }\end{array}$ & 5 & 1 & 5 & SA 1 \\
\hline Intensificação de projetos de pesquisa próprios e a associação com redes científicas e acadêmicas no Brasil e no exterior. & 1 & 2 & 2 & $\mathrm{SA} 2$ \\
\hline $\begin{array}{l}\text { Participação em importantes fóruns.A empresa é uma das representantes da indústria brasileira no comitê que discute normas padrão da } \\
\text { 1SO 26000, que fixará diretrizes para classificar empresas socialmente responsáveis. }\end{array}$ & 5 & 2 & 10 & $\mathrm{SA} 2$ \\
\hline $\begin{array}{l}\text { Elaboração de casos produzidos pela Harvard University, London Business School e pelo Institut Européen d'Administration des Affaires } \\
\text { (Insead),que vêm se somar a dezenas de outros,aceitos e estudados em escolas internacionais e brasileiras de primeira linha }\end{array}$ & 2 & 2 & 4 & $\mathrm{SA} 2$ \\
\hline $\begin{array}{l}\text { Implantação da Agenda } 21 \text { em suas unidades que está a cargo de um grupo tripartite, formado por representantes da iniciativa privada, } \\
\text { da sociedade civil e do governo local. Sensibilizou a comunidade para a importância de sua participação na elaboração do plano diretor } \\
\text { da cidade e, então, mobilizá-la }\end{array}$ & 4 & 2 & 8 & $\mathrm{SA} 1$ \\
\hline $\begin{array}{l}\text { Participa da discussão de temas específicos relacionados ao negócio,por meio de entidades setoriais às quais está associada,como a Associação } \\
\text { Brasileira da Indústria de Higiene Pessoal, Perfumaria e Cosméticos (ABIHPEC) e a Associação Brasileira de Empresas de Vendas Diretas (ABEVD) }\end{array}$ & 1 & 2 & 2 & $\mathrm{SA} 2$ \\
\hline
\end{tabular}

Tabela 2. Evidências de práticas empresariais sociais, perspectivas: processos internos, clientes e financeiro.

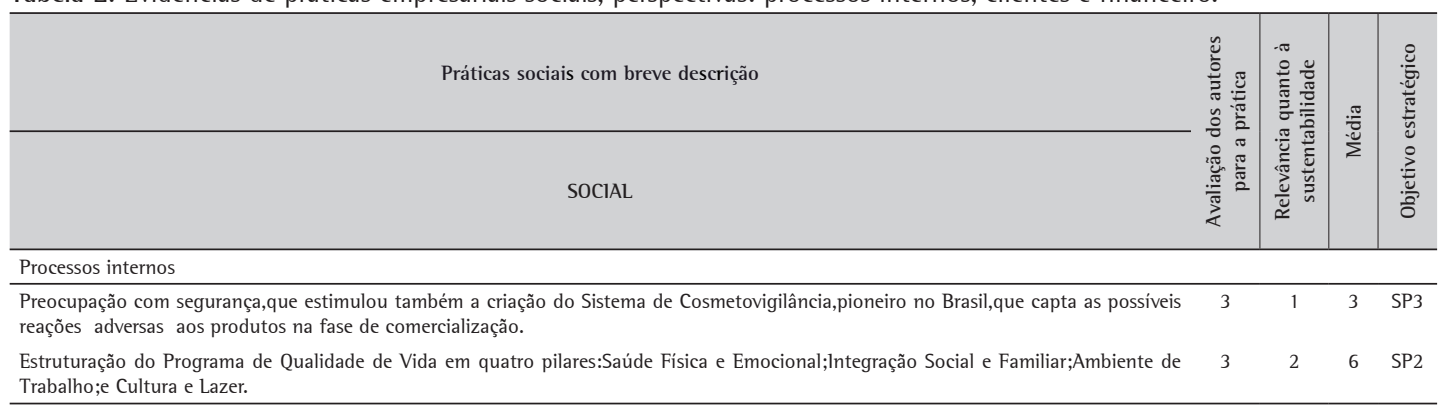


Tabela 2. Continuação...

Práticas sociais com breve descrição

\section{SOCIAL}

Em relação à ocorrência de trabalho infantil ou forçado,todos os contratos de prestação de serviço firmados pela empresa contam com cláusulas específicas para coibir essas práticas.São formalmente auditados os fornecedores que historicamente apresentam risco significativo de ocorrência.

Possui Programa Oficial de Educação Previdenciária,por meio de termo de cooperação da Associação Brasileira de Empresas de Vendas Diretas,ABEVD,com o objetivo de sensibilizar as vendedoras a contribuir para a Previdência Social.

Tem código de ética e transparência e mantém canais de diálogo abertos com os vários públicos que interagem com a companhia.

Tem uma Matriz de Investimentos em Responsabilidade Corporativa, que permite destacar o conjunto de ações que não dizem respeito à legislação nem ao negócio,mas existem para melhorar os relacionamentos e a qualidade de vida das pessoas, o monitoramento da qualidade do relacionamento da empresa com seus públicos no que diz respeito à ética, à transparência e à eficiência do canal de diálogo, à promoção do desenvolvimento sustentável - seja local, numa região específica, seja promovendo a diversidade, a educação, a qualidade de vida e a cultura (linha Econômico-social) e proteção do meio ambiente (linha Ambiental).

Processos de governança corporativa definidos e divulgados.

Existência de um Comitê de Ética, cuja finalidade é acolher e avaliar casos específicos que extrapolem a alçada da Ouvidoria.

Projetos desenvolvidos para assegurar eficiência ao sistema de gestão compartilhada, mesmo com o grande crescimento do quadro de colaboradores.

Observação das normas do Conselho de Autorregulamentação Publicitária e dos códigos de conduta da Associação Brasileira de Anunciantes e da Associação Brasileira de Defesa do Consumidor.

Clientes

Divulgação dos principais relatórios de responsabilidade social empresarial.

Utilização de meios de comunicação diversos para tornar públicas as iniciativas de cunho social.
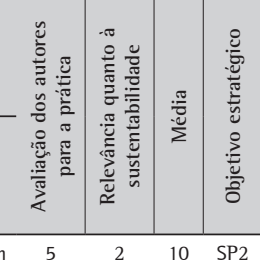

Financeiro

Na área do desenvolvimento sustentável,a empresa prioriza a iniciativas que estimulem a geração de trabalho e renda e promovam a $5 \quad 3 \quad 15 \quad$ SF1 proteção de áreas degradadas e espécies ameaçadas.

Capacitação de empreendedores locais,para que se tornem fornecedores da organização.

Estruturaça de projetos para incentivar as vendedoras e vendedores livres a recolherem as embagens de seus clientes e as encaminharem,por meio das transportadoras parceiras da organização,às cooperativas de reciclagem. Dessa forma,além de reduzir o impacto ambiental, a empresa contribui com a inclusão social e a geração de renda.

Tabela 3. Evidências de práticas empresariais com resultados econômicos, perspectiva: clientes, aprendizado e crescimento financeiro.

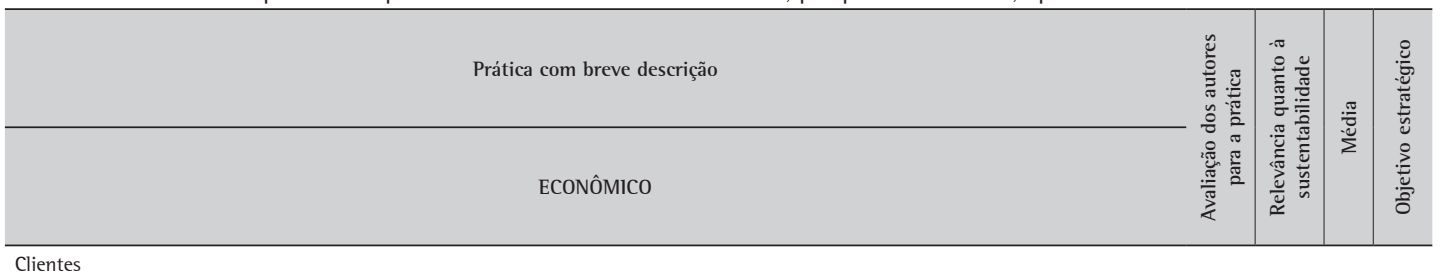

Em 2005 as ações da empresa passaram a fazer parte da carteira do IBrX100 da Bovespa, índice composto pelas 100 ações com maior liquidez do mercado à vista. A empresa também passou a figurar entre as 28 empresas que tiveram suas ações escolhidas pela Bolsa de Valores de São Paulo para compor o índice de sustentabilidade empresarial.

Busca constante pela excelência de seus produtos e serviços, essencial para o estabelecimento e a manutenção da qualidade na relação $4 \quad 4 \quad 4 \quad 16 \quad$ EC2 com os diversos públicos.

Criação de uma Central de Atendimento, um serviço telefônico gratuito, que registra pedidos e atua no gerenciamento da satisfação de $4 \quad 4 \quad 2 \quad 8 \quad$ EC1 vendedoras e vendedores livres.

\section{Financeiro}

Protegidas de dívidas adquiridas em moeda estrangeira por operações de hedge cambial. Não efetuar operações na BM\&F com caráter $4 \quad 4 \quad 2 \quad 8 \quad$ EF2 especulativo.

\begin{tabular}{|c|c|c|c|c|}
\hline \multicolumn{5}{|l|}{ AMBIENTAL } \\
\hline \multicolumn{5}{|l|}{ Aprendizado e crescimento } \\
\hline $\begin{array}{l}\text { Adoção de um modelo para garantir a extração sustentável vem sendo construído pela empresa em parceria com as próprias comunidades, } \\
\text { ONGs e governo. }\end{array}$ & 5 & 1 & 5 & AA2 \\
\hline $\begin{array}{l}\text { Para garantir segurança à saúde humana e ao meio ambiente, a empresa tem políticas de elimínação ou restrição de uso de alguns insumos } \\
\text { do portfólio de produtos e veta o uso de matérias-primas obtidas de vegetais cultivados por meio de práticas que envolvam Organismos } \\
\text { Geneticamente Modificados (OGMs). }\end{array}$ & 5 & 1 & 5 & AA2 \\
\hline $\begin{array}{l}\text { Em articulação com a Secretaria Municipal de Planejamento e Meio Ambiente, a empresa apoia a capacitação técnica dos gestores } \\
\text { municipais do programa de coleta seletiva do municipio e a formação do grupo que irá compor a cooperativa para a coleta porta a porta. } \\
\text { Apoiou, ainda, a capacitação de } 39 \text { escolas da rede pública da cidade, que, monitoradas por consultoria especializada, implementaram } \\
\text { projetos de coleta seletiva de lixo e de consumo sustentável. }\end{array}$ & 4 & 2 & 8 & AA 1 \\
\hline $\begin{array}{l}\text { Com o objetivo de assegurar que os princípios de sustentabilidade permaneçam íncorporados por esses fornecedores, a Natura apoia o } \\
\text { desenvolvimento e a implantação de modelos de produção orgânica e biodinâmica, sistemas agroflorestais e de agricultura sustentável } \\
\text { Todos se utilizam de técnicas capazes de contnbuir para aumentar a fertilidade do solo e a conservação da biodiversidade, como o manejo } \\
\text { ecológico de pragas e doenças, rotação de culturas, manejo tradicional, uso de adubação verde e consórcio de espécies. }\end{array}$ & 4 & 2 & 8 & AA2 \\
\hline
\end{tabular}


Tabela 4. Evidências de práticas empresariais ambientais, perspectivas: processos internos.

\begin{tabular}{|c|c|c|c|c|}
\hline Prática com breve descrição & 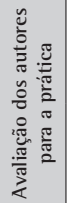 & 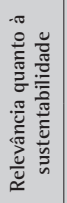 & $\sum_{\frac{\pi}{2}}^{\frac{\pi}{2}}$ & 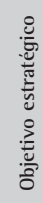 \\
\hline \multicolumn{5}{|l|}{ Processos internos } \\
\hline "Vegetalização" de toda a linha de sabonetes, agora produzida com base de óleo de palma em lugar de gordura animal. & 3 & 1 & 3 & AP1 \\
\hline Fim dos testes em animais. & 5 & 1 & 5 & AP3 \\
\hline $\begin{array}{l}\text { Em 2006, iniciou-se o plano de manejo para reconstituir a vegetação natural dos locais onde se mantém operação. Em uma reserva } \\
\text { florestal, com } 15 \text { mil m², substituíram-se eucaliptos e pinheiros por árvores nativas da região, como aroeira, jatobá, cedro e ipê-amarelo. } \\
\text { Com o objetivo de recompor a fisionomia original da Mata Atlântica, iniciou-se a substituição de árvores exóticas e de eucalipto por } \\
\text { vegetação nativa na reserva de } 130 \text { mil m² que mantemos em outra localidade. }\end{array}$ & 5 & 1 & 5 & AP1 \\
\hline $\begin{array}{l}\text { Uso sustentável de ativos da biodiversidade brasileira como plataforma tecnológica, a adoção de um processo de avaliação socioambiental } \\
\text { de fornecedores e o desenvolvimento de embalagens de menor impacto ambiental, entre outros. }\end{array}$ & 5 & 2 & 10 & AP2 \\
\hline Desenvolvimento de embalagens com ciclos de vida mais curtos e melhor biodegradabilidade. & 5 & 2 & 10 & AP2 \\
\hline $\begin{array}{l}\text { A organização se esforça para conscientizar seus fabricantes de equipamentos a produzir máquinas com menor consumo de água, energia e } \\
\text { gás refrigerante, assim como para que utilizem materiais reciclados em seus processos de fabricação e embalagem. }\end{array}$ & 4 & 2 & 8 & AP3 \\
\hline $\begin{array}{l}\text { Implantou um projeto de alteração de combustivel na frota de uma parceira Transportadora, parceiro da empresa no atendimento à região } \\
\text { da capital de São Paulo. } 0 \text { combustivel dos veículos de pequeno porte foi alterado de gasolina para GNV (95\%) e álcool (5\%) (GRI EN29). }\end{array}$ & 5 & 2 & 10 & $\mathrm{AP} 3$ \\
\hline $\begin{array}{l}\text { Entre as medidas adotadas para a redução de consumo, destaca-se não só a instalação de um número maior de hidrômetros, para monitorar } \\
\text { o consumo mais detalhadamente, como vários projetos para racionalizar o uso de água em lavagens sanitárias e de equipamentos das } \\
\text { fábricas. }\end{array}$ & 5 & 2 & 10 & $\mathrm{AP} 2$ \\
\hline $\begin{array}{l}\text { Para minimizar a geração de resíduos na fonte, a organização concentrou esforços nos processos internos de manufatura, com foco na } \\
\text { redução de materiais quaternários, como as caixas de fornecedores. Foram substituídos, também, o sistema de montagem e o tipo de } \\
\text { caixa em que os produtos são enviados para vendedoras e vendedores livres e, com essa medida, reduziu-se em } 10 \text { toneladas/mês o uso } \\
\text { de material, portanto, de resíduos. }\end{array}$ & 4 & 2 & 8 & $\mathrm{AP} 2$ \\
\hline
\end{tabular}

Tabela 5. Evidências de práticas empresariais ambientais, perspectivas: clientes; financeiro.

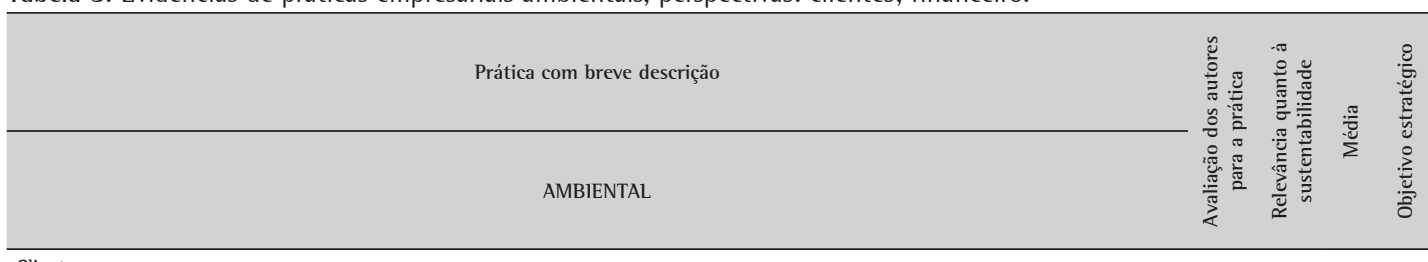

Clientes

No âmbito do relacionamento com entidades de classe, a empresa desenvolve, em conjunto com a Associação Brasileira da Indústria de Higiene Pessoal, Perfumaria e Cosméticos, Abihpec, projeto para coleta seletiva de embalagens depois de usadas. E renovou, com a Associação Brasileira de Empresas de Vendas Diretas,ABEVD, o compromisso com o Código de Conduta de Venda Direta Diante dos Vendedores Diretos e entre Empresas.

Uso de refis em itens pouco usuais, como batons, o que é relevante em termos de minimização de impacto ao meio ambiente. Suas fórmulas, desenvolvidas com avançada tecnologia, são compostas por ingredientes da biodiversidade brasileira, obtidos de maneira sustentável. Ainda nesse sentido, foi ampliado o uso de refis em outras linhas, como a de desodorantes. Em alguns produtos, foram relançadas as embalagens, que passaram a ter resinas recicladas na composição,melhorando a qualidade e a atratividade do portfolio.

A organização corrobora os princípios da Convenção da Biodiversidade e explicita essa posição quando dialoga com o governo e com a $4 \quad \begin{aligned} & 4 \\ & 8\end{aligned} \quad$ AC2 sociedade a favor de mudanças na legislação.

\section{Financeiro}

Reutilização de água e redução de resíduos incinerados. 0 total de resíduos gerados por unidade vendida, porém, cresceu 8,2\%, em razão da maior utilização de um de seus sites e, princípalmente, do aumento do sucateamento (GRI EN11 e EN13).

No plano ambiental, a empresa evoluiu em vários processos, como na implementação de um sistema para mapear emissões, identificar oportunidades de redução de gases, desde a cadeia de fornecimento ao descarte final, e gerenciar planos de ação, com o objetivo de, até 2008 , se tomar "carbono neutro", mitigando e compensando os impactos ambientais de todas as suas operações.

Implantou um sistema de Monitoramento de emissão de Gases de Efeito Estufa. 0 sistema mapeia emissões, identifica oportunidades de redução de gases, desde a cadeia de fornecimento ao descarte final, e gerencia planos de ação. Com isso, a empresa terá mais uma ferramenta para continuar a reduzir o impacto da nova operação. Um grupo multidisciplinar passou a fazer o balanço anual de emissões. No âmbito interno das fábricas e dos escritórios, a gestão da qualidade e do meio ambiente é tratada de forma conjunta no Sistema Integrado Normativo. A concepcão do sistema inclui elementos de conceitos de gestão desenvolvidos a partir das normas 1S0 9001:2000 e ISO 14001:2004, dos critérios de excelência da Fundação Nacional da Qualidade (FNQ), e das melliores práticas do mercado. Em 2006, as certificações de 1509001 e 14001 foram mantidas.

Aprofundamento do conhecimento sobre a biodiversidade brasileira e sua utilização sustentável na formulações.

Uso sustentável de ativos da biodiversidade brasileira como plataforma tecnológica, adoção de um processo de avaliação socioambiental de fornecedores e o desenvolvimento de embalagens de menor impacto ambiental, entre outros.

A empresa desenvolve processos industriais limpos, sem poluição da atmosfera. Contudo, desde 2000 toma a decisão de diagnosticar, planejar e fazer intervenções em relação a emissões atmosféricas na frota dos fornecedores que entregam os produtos Natura em mais de 5 mil municípios brasileiros. 